\title{
EFFECT OF COATING ON THE TMF LIVES OF SINGLE CRYSTAL AND COLUMNAR GRAINED CM186 BLADE ALLOY
}

\author{
S.D. Peteves, F. De Haan, J. Timm \& J. Bressers \\ Institute for Advanced Materials, JRC, European Commission \\ Petten, The Netherlands \\ $\&$ \\ P. M. Hughes \& S. J. Moss \\ ABB ALSTOM POWER UK Ltd, Leicester, UK \\ $\&$ \\ P. Johnson \& M. Henderson \\ DERA, Farnborough, UK
}

\begin{abstract}
CM186, a Hf containing nickel-base superalloy is an attractive alloy, in terms of castability and thus manufacturing costs, for aero engine and land based gas turbine applications. Mechanical property and coating characterisation studies of this alloy are sparse, whilst thermo-mechanical fatigue (TMF) data do not exist in the literature. In service however, engine components experience severe cyclic thermal gradients and mechanical loads and as a consequence, TMF is a major lifing factor. This study investigates the TMF behaviour of single crystal and directionally solidified CM186 alloy and the effect of a silicon modified aluminide coating, Sermalloy 1515 , on the TMF lives. Strain controlled TMF tests on coated and uncoated samples are carried out with an out-of-phase $180^{\circ}$ difference between mechanical strain and temperature at 3 different strain ranges. In-situ monitoring of microcrack initiation and propagation and post-mortem fractographic analysis are implemented to understand the damage mechanisms and coating performance.
\end{abstract}

\section{Introduction}

High pressure gas turbine blades are frequently made from single crystal nickel-based alloys, microstructurally designed to retain strength up to high temperatures. The absence of an expensive solution heat treatment, along with high casting yields and achievable high temperature properties, makes columnar grained (CG) (directionally solidified) CM186 an attractive alternative alloy for aero engine and land based gas turbine applications. $(1,2)$ The life of such a CG component is primarily determined by the interaction of mechanical and thermal loads and environmental contributions. Various protective measures are taken to guarantee efficient operation of the blades up to service temperatures. (3) Different coatings have been developed to protect the blades against environmental degradation. The failure modes, which must be taken into account for lifetime assessment of such coated systems include oxidation, corrosion, erosion and microstructural discontinuities caused by interdiffusion between the substrate and the coating. However, the major cause of failure is thermo-mechanical fatigue due to mechanically applied and thermally induced stresses, resulting from the thermal strains generated by the strong temperature gradients experienced during heating and cooling.

In this work, the results of TMF tests on single crystal (SC) and CG CM186 blade alloys in the uncoated and Sermalloy 1515 coated conditions are reported. Strain controlled thermo-mechanical fatigue cycles simulating the thermal and mechanical loading situation at critical locations of the blades were applied, and the damage evolution on the samples was in-situ monitored throughout the TMF cycle. 


\section{Experimental}

Specimens were machined from single crystal (SC) and columnar grained (CG) (directionally solidified) Ni-based superalloy CM186 bars with the orientation of the long axis of the samples in the [001] crystallographic direction. The nominal chemical composition in wt \% of CM 186 is given in Table 1.

Table 1. Chemical composition of CM 186 (in wt. \%)

\begin{tabular}{|c|c|c|c|c|c|c|c|c|}
\hline $\mathrm{Co}$ & $\mathrm{W}$ & $\mathrm{Al}$ & $\mathrm{Cr}$ & $\mathrm{Ta}$ & $\mathrm{Re}$ & $\mathrm{Hf}$ & $\mathrm{Ti}$ & $\mathrm{Ni}$ \\
\hline 9.25 & 8.5 & 5.7 & 6 & 3.4 & 2.95 & 1.4 & 0.7 & bal \\
\hline
\end{tabular}

Threaded end TMF specimens with a solid rectangular cross-section of $12 \times 3 \mathrm{~mm}^{2}$ and a parallel length of $9 \mathrm{~mm}$ were machined. The rectangular cross section was adopted to enable observation of the flat surface by means of a computer vision system during testing, as discussed later. The parallel section was ground and polished in the longitudinal direction to a final surface finish of $R_{z}=0.05$ $\mu \mathrm{m}$. The edges of the gauge length section were rounded to promote good adherence of the coating.

Some of the SC and CG CM186 samples were coated with a modified aluminide coating, Sermalloy 1515 , via an $\mathrm{Al} / \mathrm{Si}$ slurry diffusion process, with an approximate thickness of $80 \mu \mathrm{m}$.

The strain-controlled TMF tests wcre carried out in air on a computer controlled electro-mechanical closed loop testing machine of $100 \mathrm{kN}$ capacity. Tests with a minimum to maximum strain ratio, $R_{\varepsilon}=-\infty$. at three different strain range levels of $1 \%, 0.8 \%$ and $0.7 \%$ and a constant strain rate during the cycle were performed. The temperature varied symmetrically and linearly with time between 350 ${ }^{\circ} \mathrm{C}$ and $950^{\circ} \mathrm{C}$ with a cycle period of $200 \mathrm{~s}$. A schematic picture of the applied cycle is shown in Fig. 1.

The mechanical strain was varied synchronously and linearly with time, but with a phase shift of $180^{\circ}$ with respect to the temperature. This cycle imposes maximum strain/stress at minimum temperature and minimum strain/stress at maximum temperature. The mechanical strain rate was $\left|\mathrm{d} \varepsilon_{\mathrm{m}} / \mathrm{dt}\right|=10^{-2} \Delta \varepsilon,\left[\% \mathrm{~s}^{-1}\right]$ constant at any instant in time within the cycle. Strain was measured and controlled by means of a water cooled, high temperature axial extensometer with ceramic rods attached to the parallel length of the specimen. The original gauge length at $350^{\circ} \mathrm{C}$ was $8 \mathrm{~mm}$. The loads were measurcd by means of a strain gauged load cell located in the load train of the testing machine. Specimens were heated by means of electromagnetic induction, using a commercially available $6 \mathrm{~kW}$ high frequency induction heater and an induction coil with optimised geometry, so that the temperature gradient over the gauge length was within $\pm 15^{\circ} \mathrm{C}$ at any given time during the cycle. The sample temperature was measured and controlled by means of thermocouples spot-welded on the specimen surface. An IR-pyrometer was also used for additional monitoring of the temperature during the test.
Control of the testing machine, the high frequency induction heating system and data acquisition was performed by means of a dedicated computer system using LabVIEW 5.1. Both the cyclic stress-strain response and the thermo-mechanical fatigue life were determined. Tests were conducted until failure, or stopped when the cyclic stress range had dropped beyond $50 \%$ of the stabilised value. TMF life was then defined as the cycle number at which the stress range $\Delta \sigma$ had decreased to $50 \%$ of the stabilised or maximum value.

During TMF testing, images of the front face of the specimen were taken at pre-selected cycle numbers by means of a computer controlled video imaging system, allowing contact-less, in-situ and fully automated monitoring of the information related to the evolution of damage. To enhance the detection of initiating and growing cracks (with a surface length $\geq 15 \mu \mathrm{m}$ ), the CCD camera with a flash unit was synchronised with the TMFcycle and images were taken when the imposed stress on the specimen exceeded $80 \%$ of the maximum tensile stress of the previous cycle. The images taken covered the specimen width and $11.6 \mathrm{~mm}$ of the parallel length of the specimen. All the images were digitised and stored for post-processing and analysis.

Fractographic analysis of the tested samples was performed to obtain an understanding of the fracture in terms of initiation sites, crack propagation modes and morphologies and the relationship between fracture surface features and the microstructure of the coating and substrate alloy. Polished cross-sections of selected samples were metallographically prepared and observed under SEM and analysed by means of EDS.

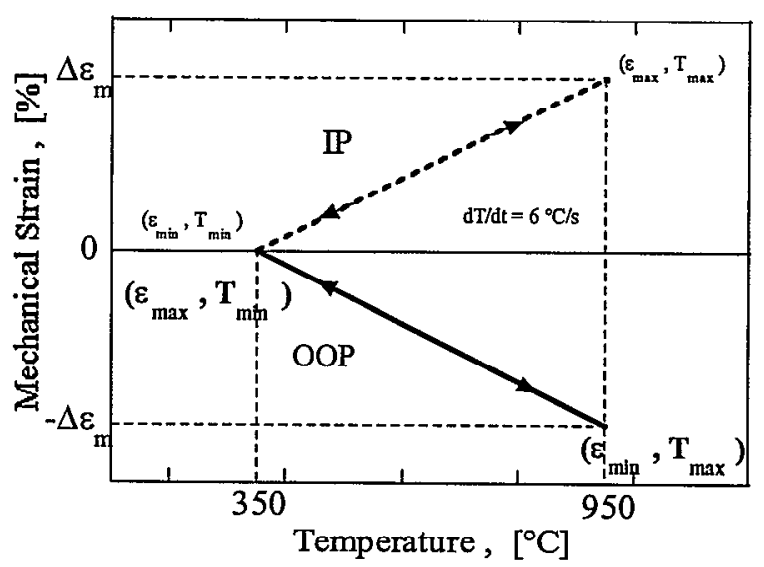

Figure 1: TMF cycle shapes in terms of mechanical strain $\varepsilon_{\mathrm{m}}$ versus temperature (IP: in phase, OOP:out-of-phase, applied in this study).

Isothermal strain controlled fatigue tests were also carried out on both solid and hollow specimens of CM186, in the CG and SC form. The solid specimens were cylindrical in section with a gauge diameter of $7 \mathrm{~mm}$. The hollow 
specimens were manufactured to the same external dimensions, but were cast with a hollow interior giving an as-cast nominal wall thickness in the gauge section of $1 \mathrm{~mm}$. Final machining included honing of the inner surface to provide a smooth finish. Testing was carried out on a servo-hydraulic machine at a strain rate of $0.1 \% \mathrm{~s}^{-1}$. A constant temperature was maintained with a radiant heat furnace. Testing was carried out at several strain ratios and temperatures up to $950^{\circ} \mathrm{C}$.

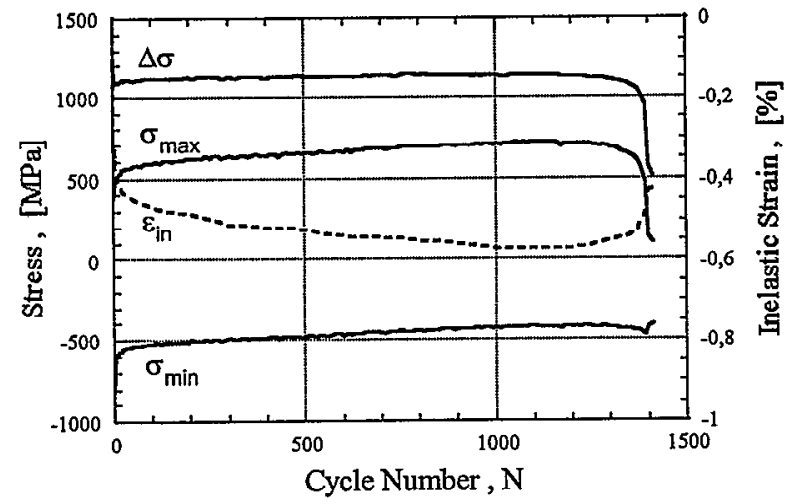

Figure 2: Evolution of the characteristic cycle stresses and accumulated inelastic strain with cycle number, $N$, measured on CG CM186 uncoated, at $\Delta \varepsilon_{\mathrm{m}}=1 \%$.

\section{Results \& Discussion}

\section{Stress-strain-temperature response}

The typical evolution of the maximum and minimum cycle stresses and the stress range with cycle number $\mathrm{N}$ during OOP TMF testing is shown in Fig. 2 for the uncoated $C G$ material at a mechanical strain range of $\Delta \varepsilon_{\mathrm{m}}=1 \%$.

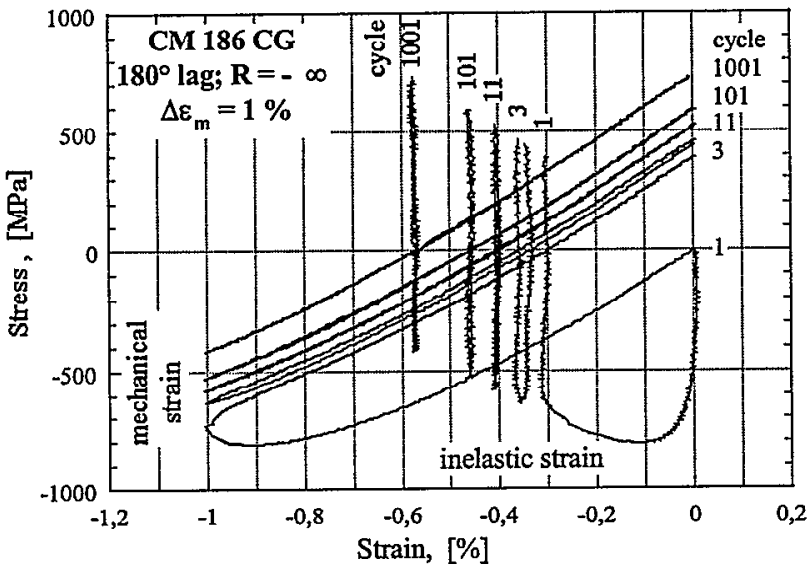

Figure 3: Stress-strain loops at three different stages during a test on CG CM186 uncoated, at $\Delta \varepsilon_{\mathrm{m}}=1 \%$.
The material does not exhibit any strong cyclic evolution. This is supported by the results from strain controlled isothermal LCF tests at several temperatures. There is a rapid shift in stress during the early TMF cycles. The pace of this process decreases with continued cycling, with the stress cycle exhibiting a positive mean value. Subsequently, extensive cracking influences the compliance. This process is entirely consistent with the dominance of plasticity and more importantly creep at the compressive/high temperature end of the cycle. This is further emphasised by the evolution of inelastic strain (Fig. 2 ). Note that the shift of $\varepsilon_{\text {in }}$ with cycling is depicted from the stress-strain loops shown in Fig. 3. After cycle 1, in which a significant amount of hysteresis is present, the build-up of $\varepsilon_{\text {in }}$ with cycling slows down. This is also commensurate with the isothermal data.

From about $\mathrm{N} / \mathrm{N}_{\mathrm{f}} \approx 0.1$ onwards, creep in the high temperature part of the cycle with stress in compression is the dominant deformation process responsible for a continuation of steady accumulation of inelastic strain. This results in a gradual shift of the compressive stress to smaller absolute values and a similar shift of the tensile stress to higher values. The shift continues until the amount of creep deformation in the compressive part of the cycle is compensated by an equivalent inelastic deformation in the tensile part of the cycle at lower temperature. However a decrease of tensile stress might already set in before this state of equilibrium is reached if the compliance of the sample increases due to crack formation and growth.

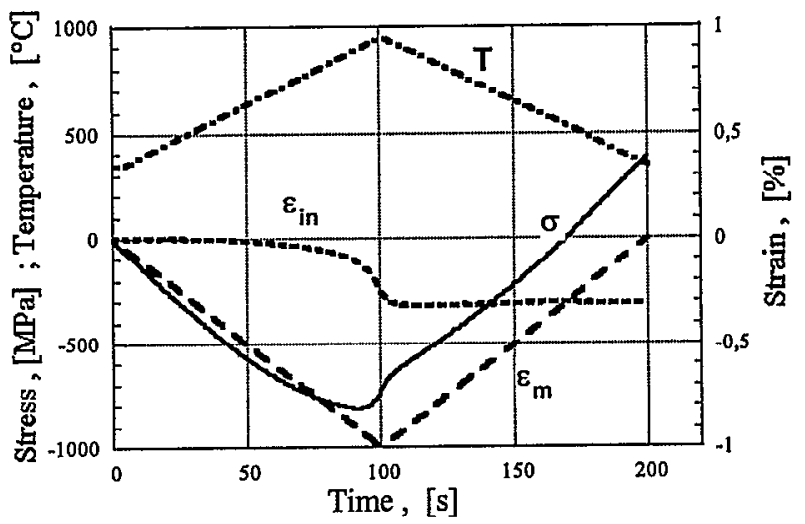

Figure 4: Stress $(\sigma)$, temperature $(T)$, mechanical strain $\left(\varepsilon_{\mathrm{m}}\right)$ and inelastic strain $\left(\varepsilon_{\mathrm{in}}\right)$ as a function of time for the first cycle; CG CM186 uncoated tested at $\Delta \varepsilon_{\mathrm{m}}=1 \%$.

Most of the inelastic strain is primarily created during the heating phase of the first cycle in compression. Fig. 4 shows the stress, temperature, mechanical and inelastic strain as a function of time in the first TMF cycle, when the CG material in the uncoated condition is tested at a strain range of $1 \%$. In the first part of the cycle a purely elastic 
increase of the compressive stress can be observed. With increasing mechanical strain and temperature, plastic flow of the material sets in. Once the yield strength of the material is reached at about $800^{\circ} \mathrm{C}$, plastic deformation occurs leading to a decrease in compressive stress with further increase of mechanical strain and temperature. The peak of the compressive stress does not correspond with the minimum mechanical strain and maximum temperature. Stress in compression was minimum at about $820^{\circ} \mathrm{C}$ while the mechanical strain reached its minimum at the maximum temperature of the cycle of $950^{\circ} \mathrm{C}$. In the second half of the cycle, with decreasing mechanical strain and temperature, the sample deforms almost exclusively elastically while the inelastic strain remains constant till the end of the cycle. The inelastic strain imposed on the specimen during the compression period should be balanced by a corresponding and equivalent deformation in tension. In this regime of low temperature, the yield strength of the material is not reached and consequently the tensile stress increases almost exclusively elastically. By the third and fifth cycles a different picture has emerged.

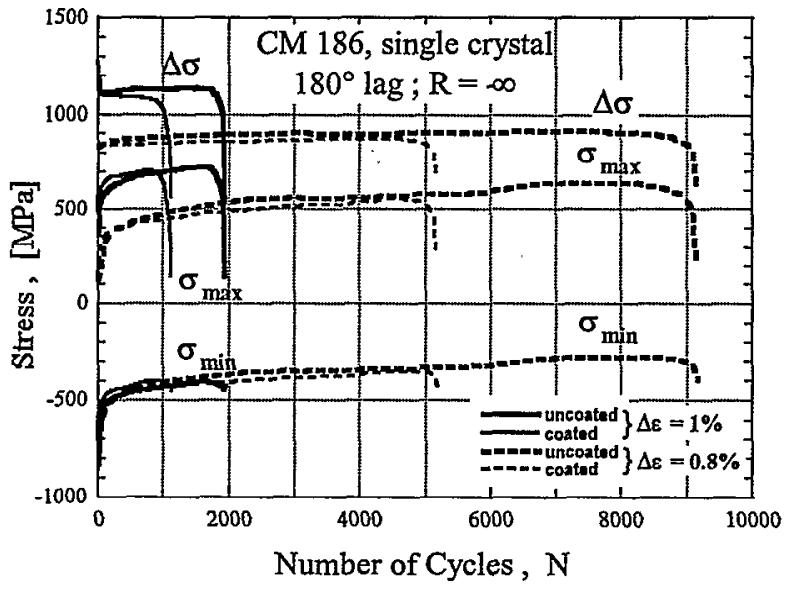

Figure 5: Evolution of stress range $(\Delta \sigma)$, maximum stress and minimum stress with TMF cycles; uncoated and Sermalloy 1515 coated SC CM186.

The minimum of the compressive stress almost coincides with the minimum of mechanical strain. No pronounced yielding is observed and the total plastic deformation during the entire cycle is less than $0.06 \%$ and $0.02 \%$ in the third and fifth cycle, respectively. This behaviour indicates that the hysteresis loops are almost stabilised after a few cycles of the test. The pronounced inelastic deformation early in life results in a shakedown of the cyclic stresses to values close to the elastic regime, resulting in very narrow and almost closed stress-strain loops during the major part of life.

Figures 5 and 6 display the evolution of the maximum and minimum cycle stresses and the stress range with cycle number, $\mathrm{N}$, for the $\mathrm{SC}$ and $\mathrm{CG}$ material respectively, measured on specimens in the uncoated and coated condition at different mechanical strain ranges. The results show that the general deformation behaviour of the material appears to be essentially independent of whether the material is of SC or CG structure. The similar cyclic behaviour of the uncoated and coated CM186 suggests that the stress-strain response of the bulk is not influenced by the presence of the coating. Figures 5 and 6 show that, in compression all the stress data for all strain ranges coincide. At all strain ranges the yield strength of the material is reached in the high temperature compressive part of the first cycles. Thereafter, the compressive stress level is. the same for all strain levels, as there is no plastic deformation in the low temperature tensile part of the cycle. Further inelastic deformation is due to creep and approximately the same for all tests. Fig. 7 summarises the evolution of the stress range with cycle number for all tests performed. For both material structures in the bare condition and the mechanical strain ranges considered, the stress range assumes an almost constant, may be slightly increasing value up to the onset of final fracture. The result for the coated SC, at $\Delta \varepsilon_{\mathrm{m}}=1 \%$, is somewhat different, showing a progressive reduction in stress range from $20 \%$ of TMF life.

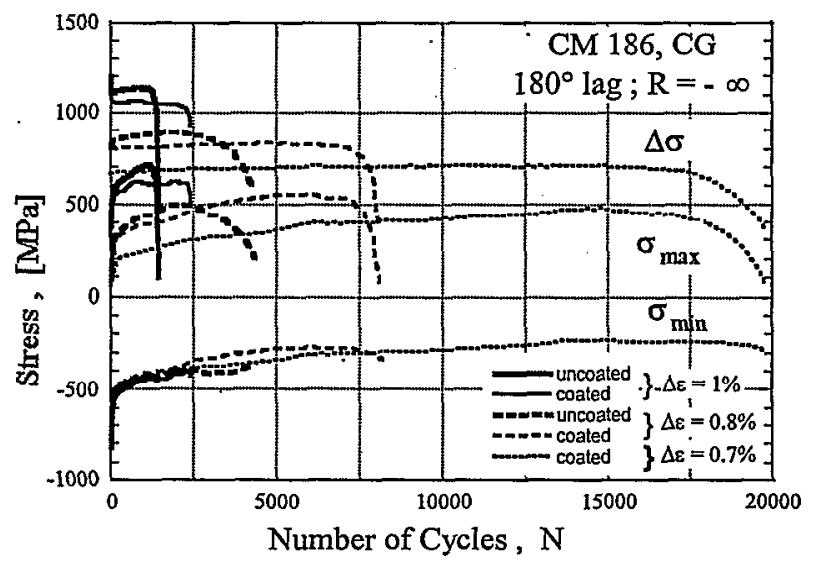

Figure 6: Evolution of stress range $(\Delta \sigma)$, maximum stress and minimum stress with TMF cycles; uncoated and Sermalloy 1515 coated CG CM186.

\section{Microstructural Analysis}

As-received state The main microstructural differences between the SC and CG materials are the presence of high angle boundaries and coarse carbides, having a Chinese script morphology, being present in the grain boundaries of the latter.

Figure 8 shows the microstructure of a coating in a state assumed "as-received" (cross-section well outside the gauge length of the shortest lived sample). The coating is approximately made up of 3 layers, each about $25 \mu \mathrm{m}$ thick, separated by 2 interlayers (ca. $5 \mu \mathrm{m})$. The dark coloured 
matrix of the layers is made up from $\mathrm{Al}$ and $\mathrm{Ni}$, with additional elements that have diffused from the substrate, while the bright precipitates and interlayers are rich in $\mathrm{Si}$. At the coating/substrate interface a substrate-affected zone can be seen, in which the $\gamma$ matrix is richer in $\mathrm{Ta}, \mathrm{W}$ and $\mathrm{Re}$ than the substrate.

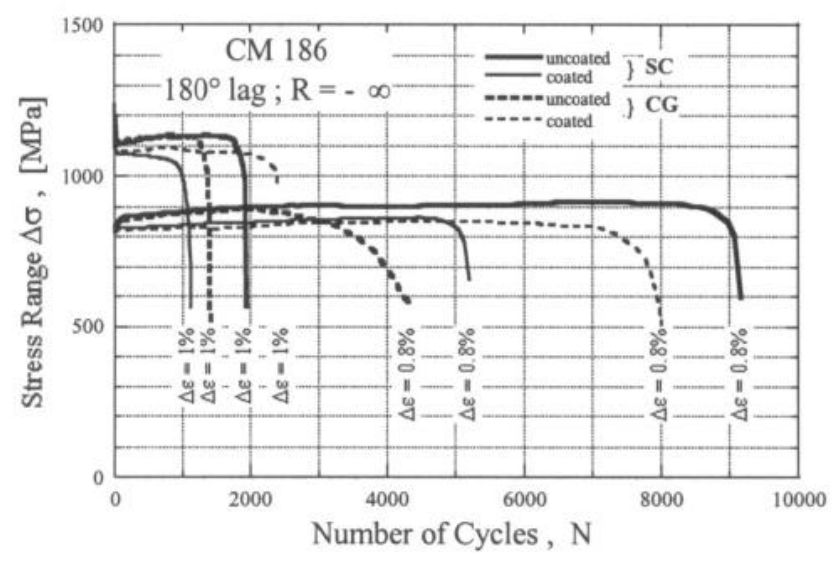

Figure 7: Evolution of the stress range with the number of TMF cycles; uncoated and Sermalloy 1515 coated SC and CG CM186.

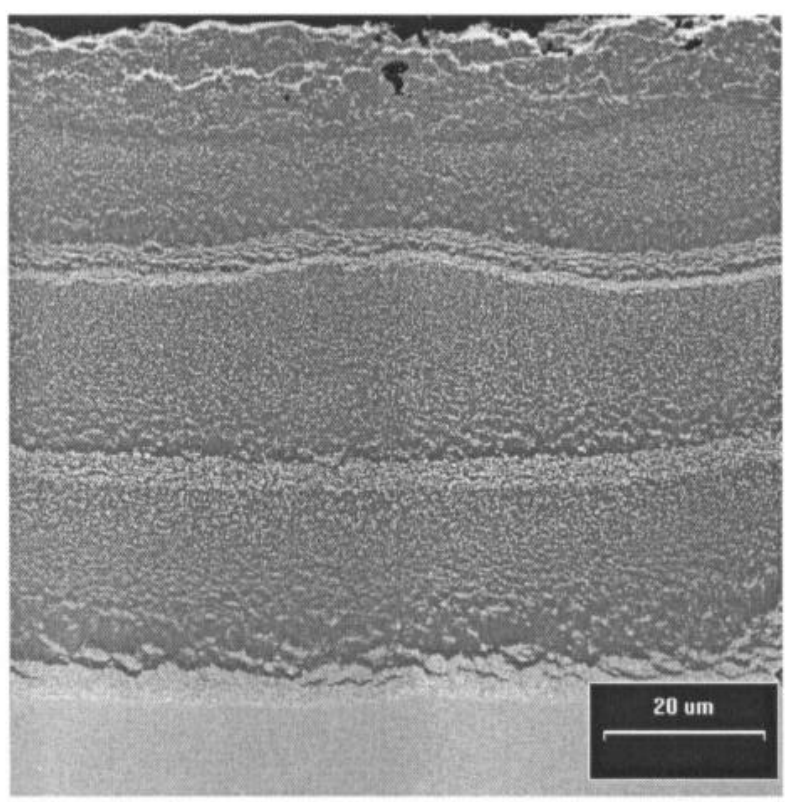

\section{TMF Lives}

In Fig. 9, the TMF lives of the SC and CG CM186 in the uncoated and Sermalloy 1515 coated condition respectively are plotted as a function of the mechanical strain range $\Delta \varepsilon_{\mathrm{m}}$. As mentioned earlier, life to failure is defined as the cycle number at which the stress range $\Delta \sigma$ has decreased to $50 \%$ of the stabilised or maximum value. In the uncoated form, the SC material appears to have a longer life when compared with the CG material. Fig. 9 also reveals the influence of the presence of the coating on the TMF lives. The presence of the coating on the SC material results in a reduction in life by a factor of about two when compared with the results from the SC material tested in the uncoated condition. The CM186 material with a CG structure shows the opposite behaviour. Sermalloy 1515 coating of the material leads to an increase in life of a factor of about two. However, the total fatigue life of the specimens can be considered to consist of two parts: A crack initiation phase and crack propagation to failure. An important aspect of this work has been the use of an in-situ video imaging system to monitor the first appearance and early growth of fatigue cracks at the specimen surface. Initiation is defined here as the cycle number $\mathrm{N}_{\mathrm{i}}$ where a crack with a length (surface projection) of approximately $30 \mu \mathrm{m}$ is first detected. This length is arbitrary and dictated by the resolution of the imaging system.

The computer vision records reveal that crack initiation takes place in relative early stages of the life below $\mathrm{N} / \mathrm{N}_{\mathrm{f}}=$ 0.25 and 0.1 when the bare material was tested at a mechanical strain range of $\Delta \varepsilon_{\mathrm{m}}=1 \%$ and $0.8 \%$, respectively. These results are also shown in Figure 9 as crack initiation lives, $\mathrm{N}_{\mathrm{i}}$. In terms of crack initiation, the CG material exhibits shorter lives than the SC in the uncoated form, whereas the coated CG material has a longer $\mathrm{N}_{\mathrm{i}}$ life than the coated SC.. Furthermore, the presence of the coating leads to shorter TMF lives for the $\mathrm{SC}$ and longer for the CG material.

The $\mathrm{N}_{\mathrm{i}}, \mathrm{N}_{\mathrm{f}}$, and $\mathrm{N}_{\mathrm{i}} / \mathrm{N}_{\mathrm{f}}$ TMF data are given in Table 2 .

Figure 8: SEM image, (back scattered mode) of the Sermalloy 1515 coating in a nearly as-received state.

Table 2. Summary of TMF data

\begin{tabular}{|l|l|l|l|l|l|l|l|l|l|}
\hline & $\mathrm{N}_{\mathrm{i}}$ & $\mathrm{N}_{\mathrm{f}}$ & $\mathrm{N}_{\mathrm{i}} / \mathrm{N}_{\mathrm{f}}$ & $\mathrm{N}_{\mathrm{i}}$ & $\mathrm{N}_{\mathrm{f}}$ & $\mathrm{N}_{\mathrm{i}} / \mathrm{N}_{\mathrm{f}}$ & $\mathrm{N}_{\mathrm{i}}$ & $\mathrm{N}_{\mathrm{f}}$ & $\mathrm{N}_{\mathrm{i}} / \mathrm{N}_{\mathrm{f}}$ \\
\hline SC & 600 & 1941 & 0.308 & 1000 & 9165 & 0.109 & & & \\
\hline SC coated & 200 & 1121 & 0.178 & 300 & 5196 & 0.058 & & & \\
\hline CG & 400 & 1412 & 0.283 & 600 & 4500 & 0.133 & & & \\
\hline CG coated & 300 & 2404 & 0.124 & 400 & 7985 & 0.05 & & 19656 & \\
\hline$\Delta \varepsilon_{\mathrm{m}}(\%)$ & \multicolumn{8}{|c|}{$1 \% .8$} & \multicolumn{3}{|c|}{0.7} \\
\hline
\end{tabular}




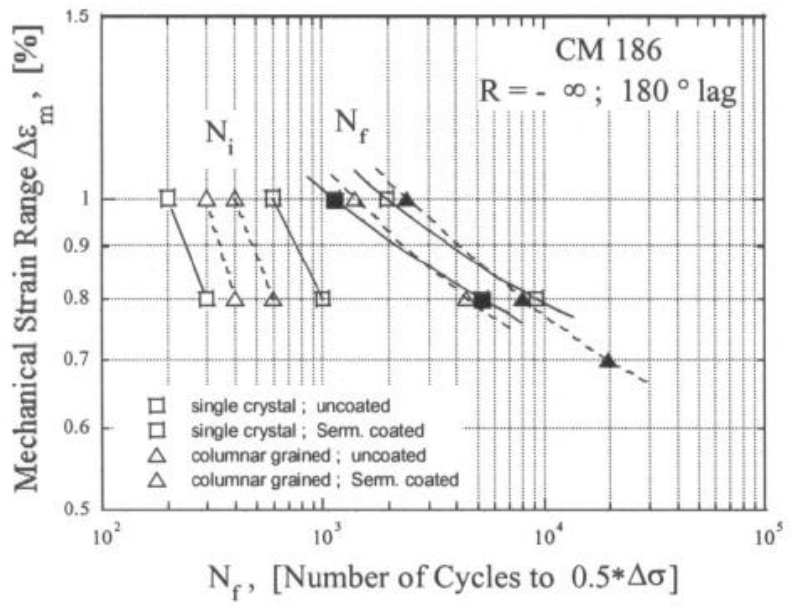

Figure 9: Cycles to failure $\left(\mathrm{N}_{\mathrm{f}}\right)$ and crack initiation lives $\left(\mathrm{N}_{\mathrm{I}}\right)$ of uncoated and Sermalloy 1515 coated SC and CG CM186 as a function of mechanical strain range.

\section{Crack Initiation and Early Growth}

The results show that, for all material and test conditions the smaller part of TMF life is spent in initiating microcracks while the larger fraction of life is spent in crack growth. Two different types of cracks are initiated and propagate during cycling as discussed also elsewhere. (4) One of these types is associated primarily with the uncoated specimens, and the other with the coated specimens.

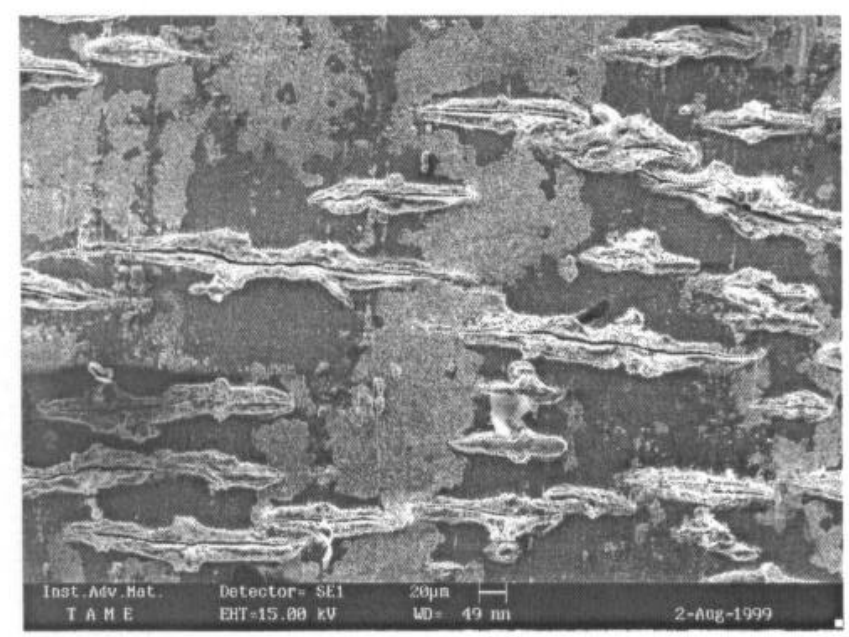

Figure. 10: Point surface initiation cracking of uncoated SC material TMF tested at a strain range of $\Delta \varepsilon_{\mathrm{m}}=1 \%$.

Uncoated Specimens In the case of the uncoated material, multiple cracks initiate at coarse microstructural features; also found were a number of examples of cracks apparently initiated at casting pores. In all cases, initiation sites are associated with cracked oxide hillocks and thus, with preferential oxidation of microstructural features. At these preferred sites, oxide hillocks protruding from the surface are formed which finally crack as shown in Fig. 10.

Small cracks are initiated with fracture surfaces approximately perpendicular to the stress axis, this is apparently invariant with $\Delta \varepsilon_{\mathrm{m}}$. The picture is similar for the SC and CG material structure, no obvious difference in initiation sites, initiation mode and density of initiated cracks could be observed. All cracks grow individually by inward extension along a semi-circular or semi-elliptical front and a crack path perpendicular to the stress axis in the radial direction. In a later stage of TMF life, coalescence of adjacent cracks starts to contribute to the extension of the cracks. Fig. 11 displays the fracture surface with some typical point-initiated, semi-elliptical surface cracks, when a CG sample was TMF tested at a mechanical strain range of $\Delta \varepsilon_{\mathrm{m}}=1 \%$.

Fractographic examinations of isothermally fatigued uncoated LCF specimens tested at $950^{\circ} \mathrm{C}$ have revealed similar results. Multiple initiation takes place at surface features rich in nickel and oxygen. This contrasts with the observations of lower temperature isothermal LCF tests where fatigue crack initiation is limited to either a few or single sites located at the surface or at sub-surface positions. These are generally found to be either pores or surface breaking brittle phases rich in hafnium, tantalum and tungsten. It can therefore be concluded that the crack initiation sites found in the TMF specimens are characteristic of those found in high temperature LCF tests for this material.

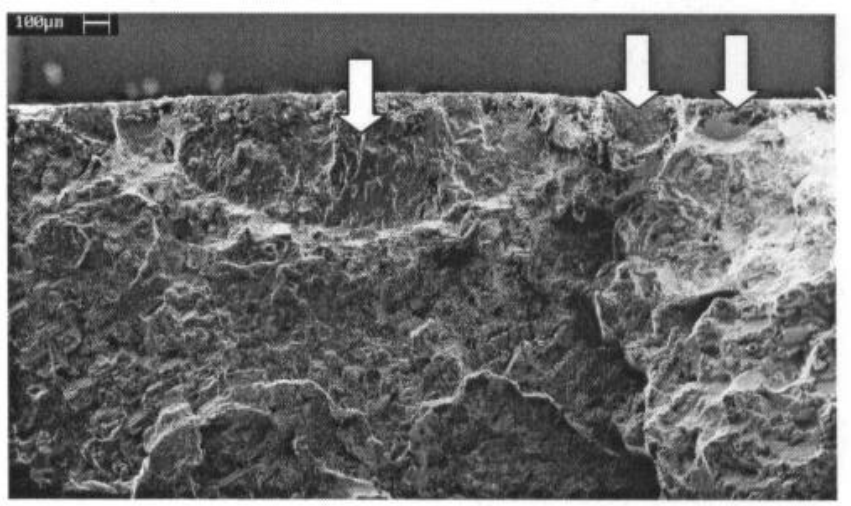

Figure 11: Fracture surface of uncoated CG material tested at a strain range of $\Delta \varepsilon_{\mathrm{m}}=1 \%$ with typical semi-elliptical surface cracks

Branching of cracks was found in the case of the CG material as shown in Figure 12, in which an example of a crack interacting with a precipitate is shown. On the other hand in the SC material, cracks grow straight and normal to the loading axis. 


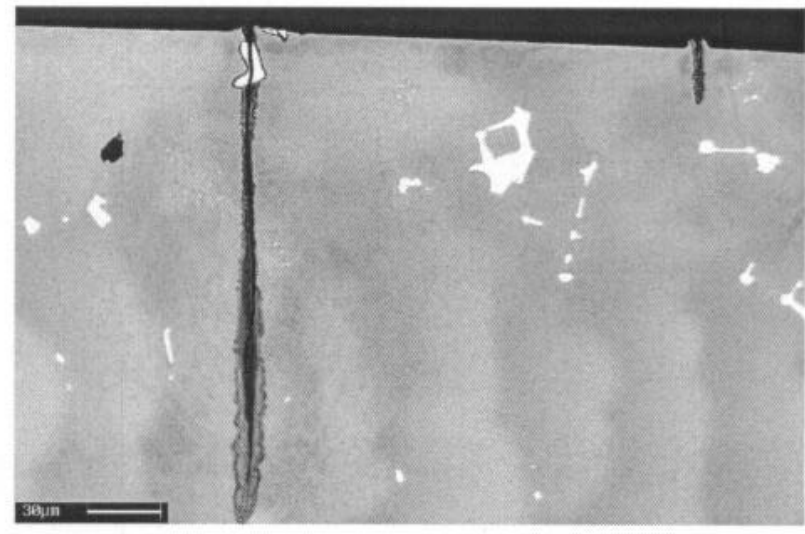

(a)

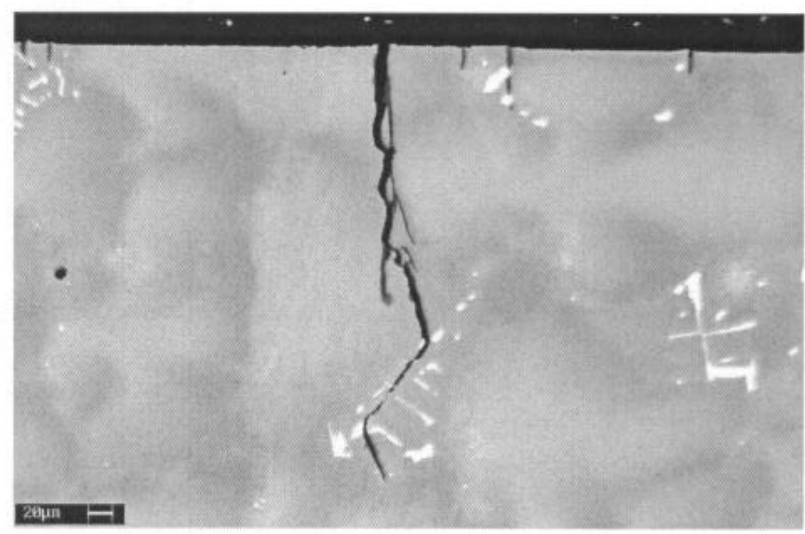

(b)

Figure 12: Observed crack paths in uncoated SC (a) and CG (b) material showing interaction with precipitates.

The fraction in life spent for initiation and propagation in the uncoated material is comparable for the SC and the CG structure but cracks appear to be initiated at a smaller number of cycles in case of the CG material when compared with the SC structure, see Fig. 9. The crack initiation earlier in life probably accounts for the lower TMF life of the CG material. There is no evidence that differences in the microstructure account for the difference in TMF lives. Further analysis of the computer vision system data with respect to evolution of crack length and crack density as a function of cycle number $\mathrm{N}$ may reveal any differences that exist between the initiation lives and crack propagation rates for the CG structure and the SC material, respectively.

Coated Specimens For the coated material, brittle fracture of the coating in a line mode is observed at all strain range levels tested. Long shallow cracks are initiated over relatively large distances relative to the specimen width, Fig. 13. It is generally agreed that the applied cycle which imposes a compressive strain on the coating at high temperature and tension at low temperature is the most damaging one.(5) Due to the accumulation of inelastic deformation in the high temperature compressive part of the cycle an increasing tensile stress is built up in the low temperature part of the cycle. Brittle cracking of the coating resulting in the formation of line cracks occurs once the limit of ductility of the coating below the ductile to brittle transition temperature, DBTT, is exceeded. (6-8)

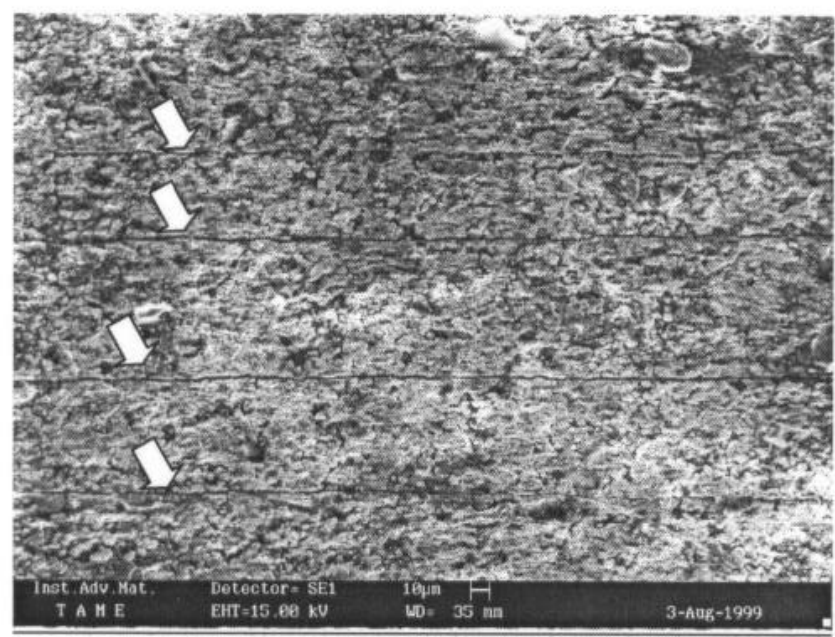

Figure 13: Surface view of Sermalloy 1515 coated CG material TMF tested at a strain range of $\Delta \varepsilon_{\mathrm{m}}=0.8 \%$ showing a system of parallel line initiated straight cracks spanning the entire surface.

Cracks are always initiated in the coating or at the surface of the coating and propagate into the substrate by Mode I extension producing a crack front almost parallel to the specimen surface and a crack path perpendicular to the loading direction, see Fig. 13. $(8,9)$ Crack nucleation sites could not be discerned by means of fractographic investigation of the fracture surface. Whether the crack starts at the outer coating surface or in the coating itself could not be identified. The overall picture of crack growth mode and morphology as shown in Fig. 13 is similar when the SC and the CG materials are tested in the coated condition.

Observations of cross-sectioned coated samples show that most of the cracks stop at the coating/substrate interface, suggesting an abrupt change of mechanical properties at this site, Figure 14. There appear to be more shallow cracks, i.e. not propagating as deeply in the substrate, in the CG material than in the SC, which could justify the enhanced TMF life of the CG coated material. Other mechanisms that could reduce $\Delta \mathrm{K}_{\text {eff }}$ and thereby reduce overall crack growths in the coated CG materials could not be discerned. The crack initiation lifetimes, Fig. 9, and the differences of maximum stress at half-life for the same applied mechanical strain are unlikely to produce 
significant differences in crack growth rates during the propagation phase.

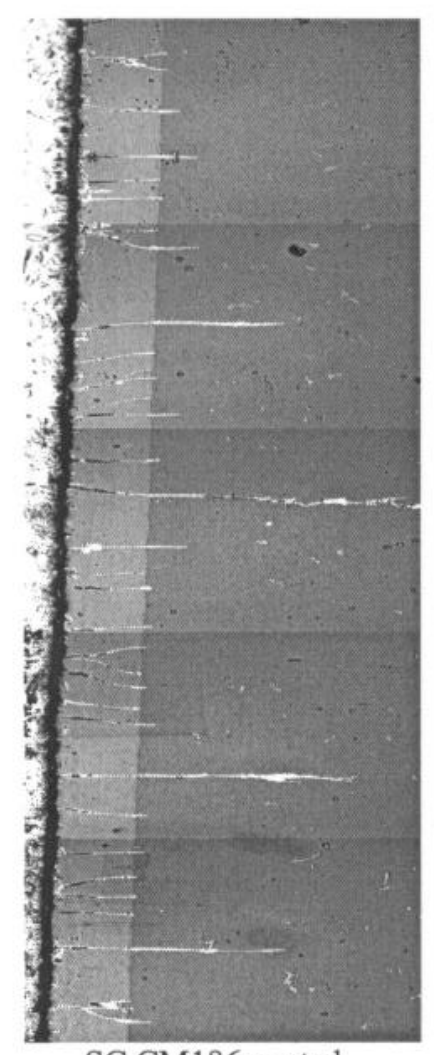

SC CM186 coated

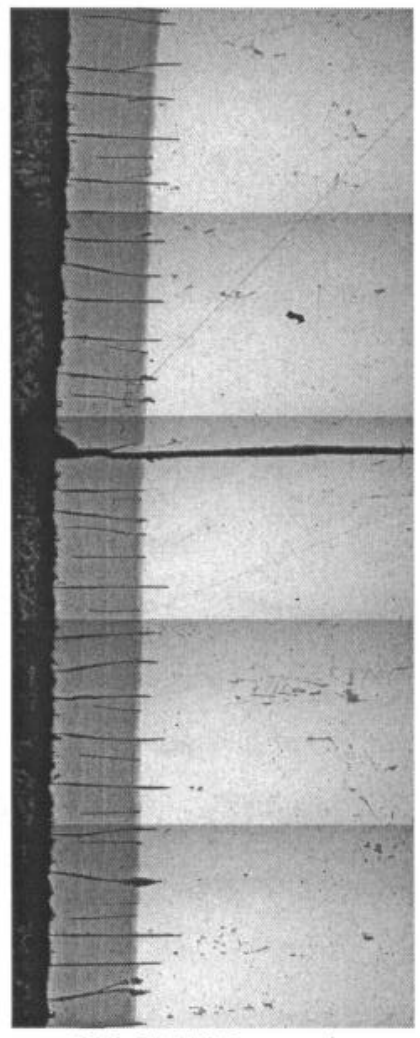

CG CM186 coated
Figure 14. Optical microscopy images of longitudinal cross sections of Sermalloy 1515 coated SC and CG CM186 alloys TMF tested at a strain range of $\Delta \varepsilon_{\mathrm{m}}=1 \%$

For both material structures, crack initiation is observed to occur after a life fraction $\mathrm{N}_{\mathrm{i}} / \mathrm{N}_{\mathrm{f}}$ of 0.15 and 0.05 for the strain range of $\Delta \varepsilon_{\mathrm{m}}=1 \%$ and $0.8 \%$, respectively. In terms of absolute cycle numbers crack initiation appears to take place earlier in life for the coated SC material relative to the CG material, see Fig. 9 and Table 2. As for the SC material the coating results in a reduction of the cycles to crack initiation $\mathrm{N}_{\mathrm{i}}$ by a factor of three for both strain range levels investigated. The formation of line cracks earlier in life and the more detrimental effect of propagating line cracks relative to semi-circular or semi-elliptical cracks (in terms of $\Delta \mathrm{K}$ ) explains the life reducing effect of the coating.

In contrast, a life lengthening effect of the coating is observed in the case of CG material. The number of cycles to crack initiation is only slightly lower for the coated material relative to the uncoated. No explanation is found yet for the longer lives of the coated material. In a number of studies into the TMF behaviour of nickel-based superalloys the presence of the coating is reported as detrimental or beneficial to TMF life. $(5,7,10-13)$ The lives to failure of the coated CG TMF specimens are shown, alongside the lives of isothermal LCF specimens tested under similar mechanical loads in Figure 15. This result, if not coincidental, is interesting in that it provides some support to the TMF results for the CG coated material in terms of absolute number of cycles to failure.

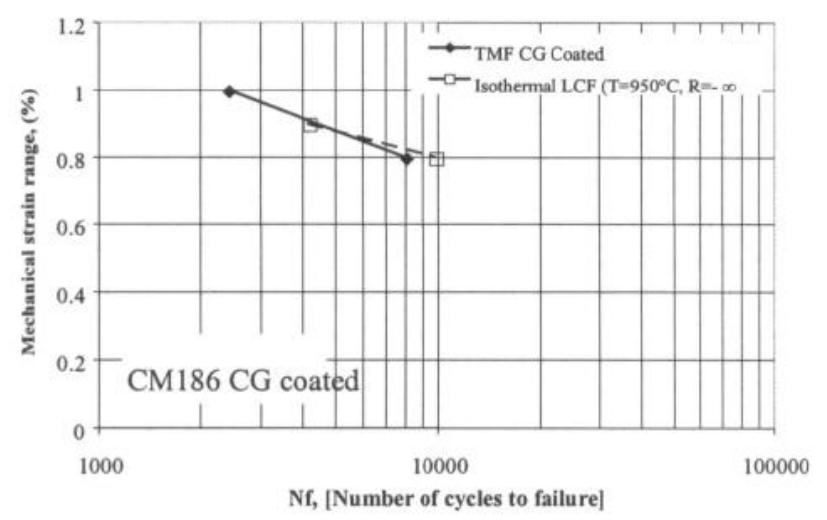

Figure 15: Comparison of TMF and isothermal LCF $\left(\mathrm{T}=950^{\circ} \mathrm{C}\right)$ results in terms of cycles to failure for coated CG CM186.

\section{Conclusions}

TMF tests on single crystal and columnar grained CM186 alloy in the uncoated and Sermalloy 1515 coated state were performed. The results suggest that the SC material has a longer TMF life than its CG counterpart. However, the effect of the presence of the coating is different for the two materials, namely enhancing the TMF life of the CG materials and degrading that of the SC. In-situ monitoring of the initiation and early growth of surface cracks have demonstrated that valuable information can be obtained on the basis of crack initiation and, thus, for lifing purposes. Initiation life represents a small fraction ( 0.1 to 0.25$)$ of the total TMF life.

The type of crack initiation is similar in the SC and CG forms of CM186, even though the numbers of cycles to initiation are different. Brittle cracking of the coating manifests itself by continuous planar surface cracks, whereas in the uncoated material cracks develop from points in a semi-elliptical form. 


\section{ACKNOWLEDGEMENTS}

Part of this work is carried out within the Commission research and development programme. PMH, SJM, PJ and MH would like to acknowledge support by the Department of Trade and Industry (UK) under the CARAD (civil aircraft research and demonstration) initative.

\section{REFERENCES}

1. K. Harris, G.L. Erickson, S.L. Sukkenga, W.D. Brentall, J.M. Aurrecoechea and K.G. Kubarych, "Development of the rhenium containing superalloys CMSX-4 \& CM186LC for single crystal blade and directionally solidified vane applications in advanced turbine engines," TMS-AIME, $7^{\text {th }}$ International Symposium on Superalloys, Seven Springs, Champion, PA, USA, September 20-24, 1992.

2. P.S. Burkholder, M.C. Thomas, R. Helmink, D. J. Frasier, K. Harris and J. B. Wahl, "CM 186 LC@ Alloy Single crystal turbine blades," ASME, 99-GT-379

3. J.R. Nicholls, "Designing Oxidation-Resistant Coatings" J. of Metals, 52(2000), 28-35

4. J. Bressers, J. Timm, S. Willimams, A. Bennett, E. Affeldt, "Effects of Cycle Type and Coating on the TMF Lives of a Single Crystal Nickel-based Gas Turbine Blade Alloy", Thermo-mechanical Fatigue Behaviour of Materials, $2^{\text {nd }}$ Volume, eds. M.J. Verrilli and M.G. Castelli (ASTM STP 1263, American Society for Testing and Materials, Philadelphia, 1995).

5. G.A. Swanson, I. Linask, D.M. Nissley, P.P. Norris, T.G. Meyer and K.P. Walker, $2^{\text {nd }}$ Annual Status Report, NASA-CR-179594, 1987.

6. J.M. Martinez-Esnaola, M. Arana. J. Bressers, J. Timm, A. Martin-Meisozo, A. Bennett, E. Affeldt, "Crack Initiation in an Aluminide Coated Single Crystal during TMF", Thermo-mechanical Fatigue Behaviour of Materials, $2^{\text {nd }}$ Volume, eds. M.J. Verrilli and M.G. Castelli (ASTM STP 1263, American Society for Testing and Materials, Philadelphia, 1995).

7. J. Bressers, J.M. Martinez-Esnaola, A.M. MartinMeisozo, J. Timm, M. Arana, "Effects of Cycle Type and Coating on the TMF Lives of a Single Crystal Nickel-based Gas Turbine Blade Alloy", Thermomechanical Fatigue Behaviour of Materials, $2^{\text {nd }}$ Volume, eds. M.J. Verrilli and M.G. Castelli (ASTM STP 1263, American Society for Testing and Materials, Philadelphia, 1995).

8. Zhang Detang, "Effect of ductile-brittle transition temperature of Al-Si coating on fatigue properties of
Ni-base superalloys", Acta Metall. Sin. Series A 3, 435 $-438,(1990)$.

9. M.I. Wood, "Mechanical interaction between coating and superalloys under conditions of fatigue", Surface and Coatings Technology, 39/40, 1989, pp. 29-42.

10. K.R. Bain, "The Effect of Coatings on the Thermomechanical Life of a Single Crystal Turbine Blade Material", (Paper presented at the ALAA/SAE/ASME/ASEE $21^{\text {st }}$ Joint Propulsion Confercnce, Monterey, Ca, July 8-10, 1985)

11.H. Bernard, L. Remy, "Thermal-Mechanical Fatigue Damage of an Aluminide Coated Nickel Base Superalloy", Advanced Materials an Processes, eds. $\mathrm{H}$. Exner and V. Schumacher, (EUROMAT, 1989), 529534.

12.J.C. Lautridou, J.-Y. Guedou and J. Delautre, "Comparison of Single Crystal Superalloys for Turbine Blades through TMF Tests", Fatigue under Thermal and Mechanical Loading : Mechanisms, Mechanics and Modelling, eds. J. Bressers, L. Rémy, M. Steen and J.L. Vallés (Kluwer Academic Publishers, 1996), 141-150.

13. J.-Y Guedou and Y Honnorat, "Thermo-mechanical fatigue of turboengine blade superalloys", Thermomechanical Fatigue Behaviour of Materials, ASTM STP 1186, ed. H Sehitoglu, San Diego, Oct. 1991, pp. 157-175 